\title{
Language and Speech
}

http://las.sagepub.com

\section{Assimilation Violation and Spoken-Language Processing: A Supplementary Report \\ Andrea Weber \\ Language and Speech 2002; 45; 37 \\ DOI: $10.1177 / 00238309020450010201$}

The online version of this article can be found at: http://las.sagepub.com/cgi/content/abstract/45/1/37

\author{
Published by: \\ (3)SAGE \\ http://www.sagepublications.com
}

Additional services and information for Language and Speech can be found at:

Email Alerts: http://las.sagepub.com/cgi/alerts

Subscriptions: http://las.sagepub.com/subscriptions

Reprints: http://www.sagepub.com/journalsReprints.nav

Permissions: http://www.sagepub.co.uk/journalsPermissions.nav

Citations http://las.sagepub.com/cgi/content/refs/45/1/37 


\title{
Assimilation Violation
}

\section{and Spoken-Language Processing: A Supplementary Report*}

\section{Andrea Weber}

\author{
City University of New York
}

\section{Key words}

\section{Abstract}

novel popout

Previous studies have shown that spoken-language processing is inhibited by violation of obligatory regressive assimilation. Weber (2001) replicated this

progressive

assimilation

inhibitory effect in a phoneme-monitoring study examining regressive place assimilation of nasals, but found facilitation for violation of progressive assimilation. German listeners detected the velar fricative [x] more quickly when fricative assimilation was violated (e.g., *[bixt] or *[blinxən]) than when no violation occurred (e.g., [baxt] or [blu:xən]). It was argued that a combination of two factors caused facilitation: (1) progressiveassimilation creates different restriction sfor the monitoring target than regressive assimilation does, and (2) the sequences violating assimilation (e.g., *[IX]) are novel for German listeners and therefore facilitate fricative detection (novel popout). The present study tested progressive assimilation violation in non-novel sequences using the palatal fricative [ç]. Stimuli either violated fricative assimilation (e.g., *[ba:çl ]) or did not (e.g., [bi: çl ]). This manipulation does not create novel sequences: sequences like *[a:ç] can occur across word boundaries, while *[IX] cannot. No facilitation was found. However, violation also did not significantly inhibit processing. The results confirm that facilitation depends on the combination of progressive assimilation with novelty of the sequence.

\section{Introduction}

Phonological adjustment processes are common in spoken language. A prominent example is assimilation, in which a feature in a sound is altered under coarticulatory influence of neighboring segments. Rules of assimilation can be either optional or obligatory. If an assimilation rule is optional, both the assimilated and the unassimilated form are equally acceptable. In German the phrase ein Bad, 'a bath', can be realized with an alveolar nasal as [ain\# ba:t] or as [aim\# ba:t] with the nasal assimilated to the following bilabial stop /b/. If an assimilation rule is obligatory, in contrast, there is only one acceptable standard realization. In Japanese a nasal must be homorganic with a following

* Acknowledgments: This work was funded by the Max Planck Institute for Psycholinguistics, Nijmegen, The Netherlands. I thank Anne Cutler, James McQueen, and Natasha Warner for their insightful feedback regarding the preparation of this manuscript. I also thank Jennifer Hay and Adrian Simpson for helpful comments on the paper.

Addressfor correspondence: Andrea Weber, Saarland University, Department of Psycholinguistics, Building 17.1,66141 Saarbrücken, Germany; e-mail: < andweb2@yahoo.com>. 
consonant. In tombo, 'dragonfly', the final nasal of the first syllable is bilabial [m] before the bilabial /b/, while in kondo, 'this time', the nasal is alveolar [n] before the alveolar /d/. The occurrence of such assimilatory adjustments in continuous speech can provide listeners with cues for phoneme recognition.

A number of studies have investigated optional assimilation in different languages via phoneme-detection or word-recognition tasks (Gaskell \& Marslen-Wilson, 1996; Gaskell \& Marslen-Wilson, 1998; Koster, 1987; Kuijpers, van Donselaar, \& Cutler, in press; Quené, van Rossum, \& van Wijck, 1998). The results of those studies have shown that spoken-language processing is neither facilitated nor interfered with by optional assimilation in a context that licenses the change, but is inhibited by assimilation in a phonologically unviable context (for a discussion of the individual studies see Weber, 2001).

Otake, Yoneyama, Cutler, and van der Lugt (1996) investigated obligatory assimilation in Japanese. Place of articulation of a nasal differs as a function of the place of articulation of the following segment. Japanese listeners responded equally rapidly and accurately to moraic nasals irrespective of their place of articulation. When asked to respond to the following stop, however, the same listeners were sensitive to violation of the obligatory place assimilation. Their RTs in a phoneme-monitoring task were significantly slower in rule-violating items (heterorganic nasal-stop cluster) than in lawfully assimilated items (homorganic nasal-stop cluster). Thus, violation of regressive place assimilation for nasals inhibited spoken-language processing in Japanese.

Weber (2001) replicated the inhibitory effect for regressive place assimilation for nasals in German. Regressive place assimilation for nasals is obligatory within German syllables for the velar stop /k/ and the bilabial stop /p/: thus German Bank, 'bank', must be realized as [bank] not as *[bank] or *[bamk]. German Lump, 'rogue', must be realized as [lomp], not as *[lonp] or *[lunp]. German listeners were asked to listen to a list of nonwords and press a button in front of them if they detected $/ \mathrm{k} /$ or $/ \mathrm{p} /$ in any of the nonwords. They detected the target stop $/ \mathrm{k} /$ or $/ \mathrm{p} /$ more slowly in monosyllabic nonwords when the preceding nasal was not homorganic (e.g., *[fєnk], *[fєmk] or *[flonp], *[flonp]) than when it was homorganic (e.g., [fєnk] or [flomp]).

However, in the same phoneme-monitoring study, Weber (2001) found facilitation rather than inhibition for items which violated progressive fricative assimilation instead of regressive nasal place assimilation. In progressive assimilation (1), an earlier segment affects a later one, whereas in regressive assimilation (2) a later segment affects an earlier one (examples from German).
(1) Licht, 'light'
[liçt ]
lacht, 'laughs' [laxt]
(2) Bank, 'bank' [bank]
fricative is shifted to palatal place of articulation due to preceding front vowel

(3) Lump, 'rogue' [lomp]
fricative is shifted to velar place of articulation due to preceding back vowel
nasal is shifted to velar place of articulation due to following velar stop
(3) Lump, rogue $[$ lomp $]$ nasal is shifted to bilabial place of articulation due to following bilabial stop

The palatal fricative [ç] and the velar fricative $[\mathrm{x}]$ stand in complementary distribution in German: the velar fricative [x] occurs after back vowels, the palatal fricative 
[ç] after front vowels, glides, sonorant consonants, word initially, and in the diminutive suffix 'chen' (Hall, 1989). Thus, the place of articulation of a vowel specifies the place of articulation for the following fricative. It violates German fricative assimilation to realize Licht, 'light', with a velar fricative $(*[1 \mathrm{l} x \mathrm{t}]) .{ }^{1}$

In Weber's study (Experiment 3) German subjects were asked to detect the velar target fricative $[\mathrm{x}]$ in mono- and bisyllabic nonwords. Half of the nonwords violated German sequencing constraints in that either a front vowel or a consonant preceded the velar fricative (e.g., *[brxt] and *[blinxən] ). Listeners detected $[\mathrm{x}]$ more quickly in phonotactically illegal sequences (e.g., *[bixt] and *[blinxən]) than in legal sequences (e.g., [boxt] and [blu:xən]). Thus, the facilitation effect appeared in mono- and bisyllabic items, for target sounds in initial and penultimate syllable position, and for target sound preceded by either a vowel or a consonant. Acoustic measurements and control experiments excluded the possibility that the facilitation effect was due to the target fricative being acoustically more prominent.

Why was processing facilitated when a progressive assimilation rule was violated and inhibited when a regressive assimilation rule was violated? Weber argued that the reason lay in the combination of two factors. First, progressive and regressive assimilation restrict the set of possible later segments differently. For any two-segment string, listeners can develop expectations about what the second segment will be on the basis of the first segment. Regressive assimilation limits the set of possible second segments strongly. In German, for instance, there are only three consonants, that can follow the $/ \mathrm{y} /$ in $/ \mathrm{f} \varepsilon \mathrm{y}-/$ within the syllable: /k/, /s/, and /t/. Regressive assimilation therefore creates strong expectations for listeners about the identity of the upcoming segment. When regressive assimilation is violated, these strong expectations are defeated, because a segment is heard that is not a member of the small set of possible continuations. Inhibition of the unexpected item can result. Progressive assimilation, on the other hand, does not allow listeners to form strong expectations about an upcoming segment, it rather acts to specifically exclude certain continuations. In German, /bi/ can be followed by $/ \mathrm{f} /, / \mathrm{k} /, / \mathrm{l} /, / \mathrm{m} /, / \mathrm{n} /, / \mathrm{y} /, / \mathrm{p} /, / \mathrm{r} /, / \mathrm{s} /, / \mathrm{J} /, / \mathrm{t} /$, or [ç], but not by [x]. Thus, when progressive assimilation is violated only weak positive expectations are defeated. This difference in strength of expectations is true for all segment strings that result from regressive or progressive assimilation, at least in the languages tested.

The second factor responsible for facilitation lies in the degree of novelty of the illegal sequences. Although sequences like *[np], which violate nasal assimilation, can never occur within words, they do occur across word boundaries in German (e.g., mein Platz, 'my place', which only optionally assimilates to [maim\# plats]). But sequences like*[Ix] and *[nx], which violate fricative assimilation, not only have zero transitional probability within words, but also across word boundaries, since no word has initial $[x]$ in German. This makes the sequences truly novel for German listeners. Novel items can receive processing priority; they "pop out" for the listeners and facilitate detection. Such a novel popout effect has been reported in research on spontaneous visual attention

1 From the distribution alone one could assume that [ç] is the unmarked allophone. However, there is no agreement in the literature on which allophone is unmarked (for a discussion of this topic see e.g. Hall, 1992). 
(Christie \& Klein, 1996; Johnston \& Schwarting, 1996; Johnston \& Schwarting, 1997). Johnston and Schwarting (1997) found that novel items caused rapid orientation and were more accurately localizable than familiar items. They claimed that novel popout is an important adaptive process that evolved in early phylogenetic history (Johnston \& Schwarting, 1997).

If the defeat of weak expectations about the upcoming segment facilitates phoneme detection in novel sequences, then how does the defeat of weak expectations influence phoneme detection in non-novel sequences? If novel popout depends both on expectations being weak and on novel sequences, then processing should not be facilitated. But is the defeat of weak expectations sufficient to inhibit processing, as in previous studies?

Weber's study was the first study which investigated progressive assimilation. Since she tested assimilation only in novel sequences we do not know yet how processing of progressive assimilation is influenced without the additional factor novelty. The present study therefore tested the same German progressive fricative assimilation rule, but this time using the palatal instead of the velar fricative as target. In the previous paper, either a front vowel (e.g., *[bixt]) or a consonant (e.g., *[blinxən]) preceded the velar fricative in items that violated assimilation. In assimilated items, the velar fricative was preceded by a back vowel (e.g., [boxt] and [bluxxən]). In the current experiment, a back vowel preceded the palatal fricative in items that violated assimilation instead (e.g., * [ba:@l ] ). In assimilated items, the palatal fricative was preceded by a front vowel (e.g., [birçl ]). Here, as in the previous paper, it is the case that listeners cannot have strong expectations about what segment will follow the vowel. In German, /ba:/ can be followed by /f/,/v/,/w/,/k/,/g/,/l/,/m/,/n/,/p/,/b/,/r/,/s/,/z/,/s/,/t/,/d/ or [x]. ${ }^{2}$ However, the sequences violating assimilation are not truly novel in German. Sequences like [arç], although illegal within words, can occur across word boundaries (e.g., sah China, 'saw China' [za:\# çina ], or zu Chemie, 'to chemistry' [tsu:\# çermis ]). ${ }^{3}$

Bisyllables were chosen for ease of articulation for the speaker. Since sequences like [a:ç] occur across word boundaries, producing those sequences within nonwords across syllable boundaries was considered unproblematic. Listeners were not expected to detect the target fricative [ç] faster when violation of assimilation occurred. It was not clear however, whether the defeat of weak expectations in non-novel sequences would be sufficient to slow down detection of the target fricative.

2 Long vowels predominate in open syllables in German. A segment following a long vowel is therefore likely to be syllable-initial. Due to final devoicing, voiced segments can only occur in syllable-initial position in German.

3 In Standard German a small number of words, like Chemie, 'chemistry', China, 'china', Chirurg, 'surgeon', begin with the palatal fricative [ç]. 


\section{Experiment}

\section{1 \\ Method}

2.1.1

Subjects

Twenty-four students from the University of Hannover, all native speakers of Standard German, took part in the experiment. They were paid for their participation.

2.1.2

Materials

A list of 28 bisyllabic items, all German nonwords, was selected with the help of the CELEX database (Baayen, Piepenbrock, \& van Rijn, 1993; see Appendix). In 14 items the first syllable ended in one of the long front vowels /i/ or /e/, followed by the palatal fricative [ç] as the beginning of the second syllable (as in [birçl]). In 14 more items the first syllable ended in one of the long back vowels /a/ or /o/, followed by the palatal

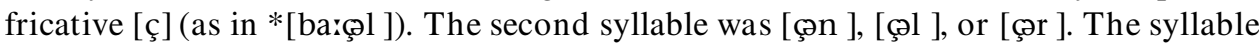

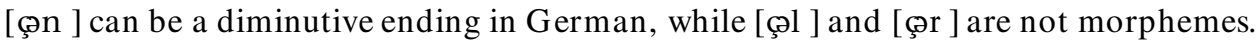
The diminutive [@̧ ] is realized with a palatal fricative not only after front vowels but also after back vowels, leading to a very small number of words with [ç] after back vowels, such as Frauchen 'mistress' [frau@̧n ]. However, almost all German nouns with a back vowel shift to a front vowel before the diminutive (e.g., Schuh-Schühchen,

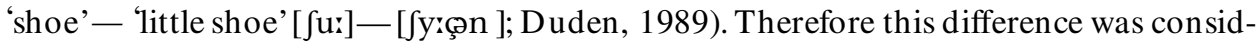
ered unlikely to have a significant influence on processing. All items were matched pairs, varying only in the backness of the first vowel. No phonotactic constraints except fricative assimilation were violated in these nonwords.

In addition, 252 mono- and bisyllabic filler items, also phonotactically legal German nonwords, were selected. Forty-two of the fillers contained the fricative [ç] in a variety of positions in the nonwords. From the complete set of 280 items, four pseudorandom orders were constructed, with the restriction that for at least two items before a target item, only fillers without the target fricative [ç] were used. Fourteen similar practice items were created.

\subsection{3}

Procedure

All materials were recorded onto a DAT in a sound-proof booth by a female native speaker of German (not the same speaker as in Weber's previous assimilation study). The materials were transferred to a computer and measured using Xwaves software. Items were presented over headphones using the NESU experiment control software. Subjects were instructed in writing and orally to listen to the nonwords and press the button in front of them as fast as possible if they detected the target fricative [ç] in one of the nonwords. The computer timed and stored reaction times (RTs). Each subject heard the practice list first, followed by one of the four experimental lists. RTs were measured from the onset of the target fricative. 


\section{2 \\ Results}

Missed responses and RTs slower than $1500 \mathrm{~ms}$ (only 4 responses) were treated as errors. Mean RTs and mean error rates are given in Table 1. Analyses of Variance with both subjects $\left(F_{1}\right)$ and items $\left(F_{2}\right)$ as the repeated measures were performed.

\section{TABLE 1}

Mean RTs in ms, measured from target onset, and mean percentage errors

\begin{tabular}{lcc}
\hline Measure & $\begin{array}{c}\text { Front vowel } \\
\text { [bi:çl] }\end{array}$ & $\begin{array}{c}\text { Back vowel } \\
\text { *[ba:@̧l] }\end{array}$ \\
\hline RTs & 547 & 564 \\
Errors & $1.7 \%$ & $0.8 \%$ \\
\hline
\end{tabular}

A two-factor ANOVA was used, with phonotactic legality (legal front vowel and illegal back vowel) and second syllable ([ڤฺ ], [ஸ̧r ], [ڤ̧l ]) as within subjects factors. In the items analysis the second syllable factor was a between items factor.

No novel popout effect was found. Subjects did not detect the palatal fricative more quickly when fricative assimilation was violated than when no violation occurred. However, no inhibitory effect was found either. Although RTs were $17 \mathrm{~ms}$ slower to items containing illegal sequences, this difference was not significant, $F_{1}(1,23)=1.92$, $p>.1 ; F_{2}<1$. The low percentage of errors indicates that the subjects had no problems performing the task. An error analysis revealed no significant effects. N either the factor second syllable $\left(F_{1}(2,46)=1.48, p>.2 ; F_{2}(2,11)=1.77, p>.2\right)$ nor its interaction with phonotactic legality showed any effect in RTs $\left(F_{1}\right.$ and $\left.F_{2}<1\right)$.

In her previous study, Weber found facilitation for processing when the fricative assimilation rule was violated by the velar fricative (Weber, 2001). Detection of the velar fricative was faster in bisyllabic nonwords containing violation of assimilation than in lawfully assimilated items. The RTs of German listeners were $535 \mathrm{~ms}$ to lawfully assimilated bisyllables (e.g., [blu:xən]) and $497 \mathrm{~ms}$ to violation items (e.g., *[blinxən]). The facilitatory effect for violation of assimilation in the velar fricative conditions was significant by subjects and by items $\left(F_{1}(1,23)=11.43, p=.003 ; F_{2}(1,13)=7.03, p=.02\right)$. A post-hoc two-factor ANOVA with phonotactic legality (legal and illegal) as a within subjects factor and target sound (velar vs. palatal fricative) as a between subjects factor was performed to compare the present results with those from bisyllables in the previous study. The interaction between phonotactic legality and target sound was highly significant by subjects and by items $\left(F_{1}(1,46)=11.55, p=.001 ; F_{2}(1,26)=14.30, p=.001\right){ }^{4}$ Thus, the pattern of responses differed significantly for violation of assimilation by the velar fricative and violation of assimilation by the palatal fricative. of Experiment 3, in which a vowel rather than a consonant preceded the fricative (e.g., *[bixt]), with the items of the present study. The results also show a highly significant interaction between phonotactic legality and target sound. 
On hearing a back vowel stimulus (e.g., *[ba:çl ]), the palatal fricative might have led listeners to interpret the vowel as vowel-r. ${ }^{5}$ In some varieties of German, the phonetic correlates of a vowel followed by $/ \mathrm{r} / \mathrm{can}$ be rather monophthongal. This interpretation would have changed the status of illegal stimuli since /barçl/ is legal in German. To test this, 10 native speakers of German listened over headphones to the recordings of all 28 target stimuli plus 28 filler stimuli which did not contain the palatal fricative. They wrote down what they heard. None of the listeners had participated in the earlier experiment (but they spoke the same variety of German as listeners in the earlier experiment did). Three listeners reported a total of $11(8 \%)$ vowel-r interpretations (e.g., *[ta:@̧n] transcribed as 'tarchen'). The other listeners did not report any vowel-r interpretation. Stimuli containing a back vowel, such as *[ba:çl], were transcribed as either 'bachel', 'baachel', or 'bahchel'. Inspection of RTs of the phoneme-monitoring experiment did not yield a different pattern for those stimuli which were transcribed as vowel-r by three listeners.

\section{General Discussion}

The present study clarifies earlier work on assimilation in spoken-language processing. A number of studies have shown that spoken-language processing is inhibited by violation of assimilation (Gaskell \& Marslen-Wilson, 1996; Gaskell \& Marslen-Wilson, 1998; Koster, 1987; Kuijpers et al., in press; Otake et al., 1996). A recent study by Weber showed that violation of assimilation can also facilitate processing under certain conditions (Weber, 2001). It was argued that facilitation occurs when two conditions are met. First, listeners must have only weak expectations about an upcoming segment, which are defeated. This is the case with violation of progressive assimilation, whereas violation of regressive assimilation rather defeats strong expectations Second, the sequences containing violation of assimilation must be novel sequences in the language. Novel items can receive processing priority; they "pop out" for the listeners and facilitate detection, as has been shown in visual attention research. Violation of the progressive fricative assimilation rule with the velar fricative meets both these conditions. If facilitation depends on novelty of the sequence, then no such effect should occur when progressive assimilation (weak expectations) is violated in non-novel sequences.

The present study therefore tested the same German progressive assimilation rule, but using the palatal fricative to create the violation instead. Sequences in which a back vowel is followed by a palatal fricative are illegal within words, but possible across word boundaries, so they are not novel in German. Listeners detected the target fricative [ç] equally quickly whether it was preceded lawfully by a front vowel (e.g., in [birçl ]) or illegally by a back vowel (e.g., in *[ba:@̧l]). Phonotactic illegality neither facilitated nor inhibited detection. If the sequence which violates assimilation defeats weak expectations but is not a entirely novel sequence, processing was not facilitated. This confirms that the previously found facilitation is indeed a novel popout effect. However, illegal sequences did not significantly inhibit processing either, which suggests that the weak expectations created about an upcoming segment are not sufficient to create strong inhibition.

5 I am grateful to reviewer Adrian Simpson for raising this possibility. 
Indirectly this attests to the importance of weak expectations for any novel popout effect. Consider that when listeners have strong rather than weak expectations, a defeat of these expectations causes strong inhibition of processing. This strong inhibition might outweigh any novelty effects. Only the defeat of weak expectations, which cause no inhibition, can cause a novel popout effect. Exactly this is confirmed by Otake et al's (1996) study on regressive place assimilation of nasals in Japanese. With regressive assimilation listeners can develop strong expectations about an upcoming segment. Furthermore, the illegal sequences were novel for the Japanese listeners, since nasals in Japanese never mismatch in place of articulation of a following stop, not even across word boundaries (Vance, 1987). Japanese listeners'RTs were significantly slower in ruleviolating items than in lawfully assimilated items. Thus, although novel sequences were involved, the defeat of strong expectations outweighed the novelty factor, and inhibition of processing resulted.

In the other relevant studies (Gaskell \& Marslen-Wilson, 1996; Gaskell \& MarslenWilson, 1998; Koster, 1987; Kuijpers et al., in press), regressive assimilation was tested with non-novel sequences. Thus, neither of the two factors responsible for facilitating processing was met, so strong inhibition of processing was shown in all four studies for assimilation violation.

The present study sheds new light on the role of the factors strength of expectations and novelty of the sequence in processing phonotactically illegal sequences. It was confirmed that only the defeat of weak expectations in novel sequences causes significant facilitation. The defeat of weak expectations of non-novel sequences did not facilitate processing, but it was not sufficient to inhibit processing, either.

Although violation of assimilation always results in phonotactically illegal sequences, the combined results show that not all illegal sequences are processed in the same way. Rather, we know now that under various circumstances processing of these illegal sequences can either inhibit or facilitate processing or not influence it at all. Hay, Pierrehumbert, and Beckman (in press) also found that not all phonotactically illegal sequences are equivalent in a judgment task where English subjects had to judge auditorily presented nonsense words as possible additions to the English vocabulary. Different sequences, all with zero transitional probability in the tested environment, were not treated equally by listeners. Rather, listeners' judgments on well-formedness of phoneme combinations were related to the overall frequency of phoneme combinations in the language. The results of the present study show that such variation among phonotactically illegal sequences applies to processing as well.

Received: October 11, 2000; revised manuscript received: December 4, 2001; accepted: February 13, 2002 


\section{References}

BAAYEN, H., PIEPEN BROCK, R., \& Van RIJN, H. (1993). The CELEX Lexical database ( $C D-R O M)$. Philadelphia: Linguistic Data Consortium, University of Pennsylvania.

CHRISTIE, J., \& KLEIN, R. (1996). Assessing the evidence for novel popout. Journal of Experimental Psychology: General, 125, 201-207.

DUDEN: DEUTSCHES UNIVERSAL WÖRTERBUCH, A-Z (1989). Bearbeitet vom wissenschaftlichen Rat unter der Mitarbeit der Dudenredaktion unter Leitung von Günther Drosdowski. 2., völlig neu bearbeitete und erweiterte Auflage. Mannheim, Wien, Zürich: Dudenverlag.

GASKELL, M., \& MARSLEN-WILSON, W. (1996). Phonological variation and inference in lexical access. Journal of Experimental Psychology: Human Perception and Performance, 22, $144-158$.

GASKELL, M., \& MAR SLEN-WILSON, W. (1998). Mechanisms of phonological inference. Journal of Experimental Psychology: Human Perception and Performance, 24, 380-396.

HALL, T. (1989). Lexical phonology and the distribution of German [ç] and [x]. Phonology, 6, $1-17$.

HALL, T. (1992). Syllable structure and syllable-related processes in German. Tübingen: Niemeyer.

HAY, J., PIERREHUMBERT, J., \& BECKMAN, M. (in press). Speech perception, wellformedness and the statistics of the lexicon. In Proceedings of 6th Conference on Laboratory Phonology. York, Great Britain: University of York.

JOHNSTON, W., \& SCHWARTING, I. (1996). Reassessing the evidence for novel popout. Journal of Experimental Psychology: General, 125, 208-212.

JOHNSTON, W., \& SCHWARTING, I. (1997). Novel popout: An enigma for conventional theories of attention. Journal of Experimental Psychology: Human Perception and Performance, 23, 622-631.

KOSTER, C. (1987). Word recognition in foreign and native language: Effects of context and assimilation. Dordrecht: Foris Publications.

KUIJPERS, C., Van DONSELAAR, W., \& CUTLER, A. (in press). Perceptual effects of assimilation-induced violation of final devoicing in Dutch. In Proceedings of 7 th International Conference on Spoken Language Processing. Denver, U.S.A.

OTAKE, T., YONEYAMA, K., CUTLER, A., \& Van Der LUGT, A. (1996). The representation of Japanese moraic nasals. Journal of the Acoustical Society of America, 100, 3831-3842.

QUENÉ, H., Van ROSSUM, M., \& Van WIJCK, M. (1998). Assimilation and anticipation in word recognition. In Proceedings of 5th International Conference on Spoken Language Processing (paper no. 113). Sydney, Australia.

VANCE, T. (1987). An introduction to Japanese phonology. Albany: State University of New York Press.

WEBER, A. (2001). Help or hindrance: How violation of different assimilation rules affects spoken-language processing. Language and Speech, 44, 95-118. 


\section{Appendix}

Targets without violation of the German fricative assimilation rule.

[birçl ], [ble:çr ], [de:çn ], [gle:çr ], [he:œ̧l ], [ke:çl ], [ki:çn ], [lirçn ], [me:œ̧l ], [ni:çr ], [pe:çr ], [pirçn ], [tirçıl ], [tiç̧n ]

Targets with violation of the German fricative assimilation rule.

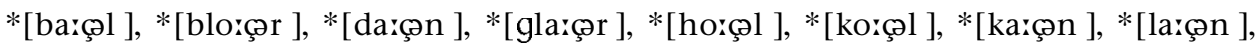

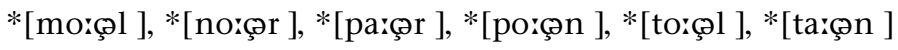

